\section{Nutrient Solution Concentration Affects Growth, Mineral Composition, Phenolic Acids, and Flavonoids in Leaves of Artichoke and Cardoon}

\author{
Youssef Rouphael \\ Department of Crop Production, Faculty of Agricultural Engineering and \\ Veterinary Medicine, Lebanese University, Dekwaneh-El Maten, Beirut, \\ Lebanon
}

Mariateresa Cardarelli

Department of Agriculture, Forestry, Nature and Energy, University of Tuscia, via San Camillo De Lellis snc, 01100 Viterbo, Italy

Luigi Lucini

Institute of Environmental and Agricultural Chemistry, Università Cattolica del Sacro Cuore, via Emilia Parmense 84, 29122 Piacenza, Italy

Elvira Rea

Agricultural Research Council, Research Centre for the Soil-Plant System, 00184 Rome, Italy

\section{Giuseppe Colla ${ }^{1}$}

Department of Agriculture, Forestry, Nature and Energy, University of Tuscia, via San Camillo De Lellis snc, 01100 Viterbo, Italy

Additional index words. biomass production, caffeoylquinic acids, Cynara cardunculus, macrominerals, phytochemicals

\begin{abstract}
A greenhouse experiment was conducted in Summer and Fall 2011 at the experimental farm of Tuscia University, central Italy, to study the effect of nutrient solution concentration $\left(4,20,36,52\right.$, or 68 mequiv $\left.\cdot L^{-1}\right)$ on biomass production, mineral composition, and concentrations of the major polyphenols in 'Romolo' artichoke and 'Bianco Avorio' cardoon grown in a floating system. Leaf dry biomass, leaf number, and macroelement concentrations (nitrogen, potassium, calcium, and magnesium) of artichoke and cardoon increased in response to an increase in the nutrient solution concentration, whereas an opposite trend was observed for the total polyphenols, phenolic acids (chlorogenic acid, cynarin, and caffeic acid), and the flavonoid luteolin. Artichoke and cardoon gave maximum biomass production and leaf number at $\mathbf{4 5}$ and 54 mequiv $\cdot \mathrm{L}^{-1}$, respectively. Cardoon showed higher biomass and leaf number (average $1.13 \mathrm{~kg} \cdot \mathrm{m}^{-2}$ and $14.0 \mathrm{n}$./plant, respectively) than those observed in artichoke (average 1.07 $\mathrm{kg} \cdot \mathrm{m}^{-2}$ and $12.7 \mathrm{n} . / \mathrm{plant}$, respectively). The chlorogenic acid, cynarin, caffeic acid, and luteolin concentrations were higher by $204 \%, 462 \%, 580 \%$, and $445 \%$ in cardoon leaf tissue than in that of artichoke. An improvement of leaf quality (total polyphenols, phenolic acids, and flavonoids) was obtained at the expense of leaf yield through the use of lower fertilizer concentrations in the nutrient solution.
\end{abstract}

Artichoke (Cynara cardunculus L.) is a complex species, belonging to the Asteraceae family, and native to the Mediterranean Basin. According to Rottenberg and Zohary (1996), it

Received for publication 18 June 2012. Accepted for publication 6 Aug. 2012.

This work was funded by the Italian Ministry of Agricultural, Food and Forestry Policies (MiPAAF), OIGA-Project "Innovative technologies for the biomass production of artichoke and cardoon to be used for the extraction of nutraceutical compounds (PRO. BIO.CA)" (D.M. n. 29627/7818/10 of 29 Dec. 2010). ${ }^{1}$ To whom reprint requests should be addressed; e-mailgiucolla@unitus.it. been found to be a rich source of polyphenolic compounds with mono- and dicaffeoylquinic acids and flavonoids as the major chemical components (Dranik et al., 1996; Wagenbreth, 1996). In various pharmacological test systems, artichoke leaf extracts have shown antibacterial, antioxidative, anti-HIV, bileexpelling, hepatoprotective, urinative, and choleretic activities as well as the ability to inhibit cholesterol biosynthesis and lowdensity lipoprotein oxidation (Brown and Rice-Evans, 1998; Dranik et al., 1996; Kraft, 1997; Martino et al., 1999). Leaf extracts have been reported to show antioxidative and protective properties against hydroperoxideinduced oxidative stress in cultured rat hepatocytes (Gebhardt, 1997), to protect lipoprotein from oxidation in vitro (Brown and Rice-Evans, 1998), to inhibit hemolysis induced by hydrogen peroxide, and to inhibit oxidative stress when human cells are stimulated with agents that generate reactive oxygen species: hydrogen, peroxide, phorbol-12myristate-13-acetate, and $\mathrm{N}$-formyl-methionylleucyl-phenylalanine (Perez-Garcia et al., 2000).

The chemical composition and quality of vegetables can be affected by many pre- and postharvest factors (Kader, 2008). The management of mineral nutrition is a key preharvest factor that determines biomass, yield, and quality of vegetable crops. Soilless culture represents an interesting tool, because it permits precise control of plant nutrition (Resh, 1997) leading to the manipulation of target compounds in plants such as phytochemicals and antioxidants. Research has established optimal ranges of total ionic concentration in the nutrient solution for the production of floricultural greenhouse crops (James and van Iersel, 2001; Mak and Yeh, 2001; Rouphael et al., 2008; Van Iersel, 1999). However, there is little information (Fallovo et al., 2009a, 2009b; Rouphael and Colla, 2009) about the optimal fertilizer concentrations for producing high-quality vegetables crops in soilless cultures.

In Italy, the artichoke for leaf extract production is traditionally cultivated in soil under high-density plantation and is mowed three times per year. Despite a relatively large interest in artichoke biomass production, advanced cultivation techniques such as a floating system have not been sufficiently considered for improving the biomass and quality of this species. The floating system, widely used for leafy vegetable production, can provide an alternative system to the traditional field cultivation of artichoke leaf, to obtain higher productivity and biomass quality, to standardize and control cultural practices, and to provide better water and nutrient supply with high environmental benefits (Fallovo et al., 2009a, 2009b).

Few studies (Fratianni et al., 2007; Lombardo et al., 2010; Wang et al., 2003) have been conducted to investigate the concentration of individual phenolic compounds in relation to genotype of artichoke and cardoon. Moreover, these studies have been focused especially on vegetatively propagated 
germplasm without considering the seeded propagated varieties. Moreover, there is lack of information on the suitability of the different genotypes to be grown in a floating system.

The objective of this study was to determine the effect of nutrient solution concentration $\left(4,20,36,52\right.$, and 68 mequiv. $\left.\mathrm{L}^{-1}\right)$ on biomass production, mineral composition, and the major polyphenols concentration in 'Romolo' artichoke and 'Bianco Avorio' cardoon cultivars grown in a floating system.

\section{Materials and Methods}

\section{Plant material and growth conditions}

The experiment was conducted in the Summer and Fall 2011 in a $300-\mathrm{m}^{2}$ polyethylene greenhouse situated on the experimental farm of Tuscia University, central Italy (lat. $42^{\circ} 25^{\prime} \mathrm{N}$, long. $12^{\circ} 08^{\prime} \mathrm{E}$, alt. $310 \mathrm{~m}$ above sea level). Plants were grown under natural light conditions. The greenhouse was maintained at daily temperatures between 12 and $30{ }^{\circ} \mathrm{C}$ and day/night relative humidity of $55 / 85 \%$.

Seeds of artichoke [C. cardunculus L. subsp. scolymus (L.) Hegi] cv. Romolo (La Semiorto Sementi, Lavorate di Sarno, Italy) and cardoon $(C$. cardunculus L. var. altilis DC.) cv. Bianco Avorio (La Semiorto Sementi) were sown on 6 Sept. 2011 into a floating raft growing system. The floating raft system consisted of polystyrene plug trays floating in plastic tanks with a constant volume of nutrient solution, which was continuously aerated with an air compressor to maintain the oxygen concentration above $6.0 \mathrm{mg} \cdot \mathrm{L}^{-1}$. The planting density was 463 plants $/ \mathrm{m}^{2}$, as used commercially for similar leafy vegetables in floating systems.

The experiment was designed as a factorial combination of five nutrient solution concentrations $\left(4,20,36,52\right.$, and 68 mequiv. $\left.\mathrm{L}^{-1}\right)$ and two crops (artichoke and cardoon). Each experimental unit consisted of a $0.1815-\mathrm{m}^{2}$ (84 plants) container filled with $65 \mathrm{~L}$ of aerated nutrient solution. The containers were not moved around during the experiment. Spacing between containers was $0.15 \mathrm{~cm}$. The treatments were arranged in a randomized complete block design with four replicates per treatment.

\section{Nutrient solution management}

In all nutrient solutions, the macroanion proportions were $0.80 \quad \mathrm{NO}_{3} / 0.12 \quad \mathrm{SO}_{4} / 0.08$ $\mathrm{H}_{2} \mathrm{PO}_{4}$, whereas the macrocation proportions were $0.30 \mathrm{~K} / 0.52 \mathrm{Ca} / 0.18 \mathrm{Mg}$, and the ratio between anions $\left(\mathrm{NO}_{3}{ }^{-}+\mathrm{SO}_{4}{ }^{2-}+\mathrm{H}_{2} \mathrm{PO}_{4}^{-}\right)$and cations $\left(\mathrm{K}^{+}+\mathrm{Ca}^{2+}+\mathrm{Mg}^{2+}\right)$ was equal to 1 . The macronutrients concentrations were 4 , $20,36,52$, or 68 mequiv. $\mathrm{L}^{-1}$. In all treatments, the micronutrients concentrations were $40.0 \mu \mathrm{mequiv} \cdot \mathrm{L}^{-1}$ iron; $18.0 \mu \mathrm{mequiv} \cdot \mathrm{L}^{-1}$ manganese; $3.0 \mu$ mequiv. $\mathrm{L}^{-1}$ copper; 6.0 $\mu$ mequiv. $\mathrm{L}^{-1}$ zinc; $60.0 \mu$ mequiv. $\mathrm{L}^{-1}$ boron; and $1.8 \mu$ mequiv. $\mathrm{L}^{-1}$ molybdenum. The $\mathrm{pH}$ of the nutrient solution for all treatments was $6.0 \pm 0.5$. All nutrient solutions were prepared using deionized water.
In all treatments the nutrient solution was changed once a week to keep nutrient levels in solution close to the initial concentrations. Consequently, the variation of the electrical conductivity and $\mathrm{pH}$ values of the nutrient solution were never greater than $5 \%$ of the initial values.

\section{Data collection and analysis}

Plant growth measurements. The leaves of artichoke and cardoon from the central part of each plot were harvested five times during the growing cycle $(23,37,51,70$, and $91 \mathrm{~d}$ after sowing). At each harvest, the leaf number per plot was recorded and the leaf tissues were dried in a forced-air oven at $60{ }^{\circ} \mathrm{C}$ for $72 \mathrm{~h}$ for biomass determination. The leaf dry biomass was expressed in $\mathrm{kg} \cdot \mathrm{m}^{-2}$. For each plot, the leaf dry biomass harvested during the growing cycle was mixed together for further mineral and quality analysis.

Mineral analysis. The dried leaf tissues were ground in a Wiley mill to pass through a 20-mesh screen and then $0.5 \mathrm{~g}$ of the dried plant tissues were analyzed for the following macro- and micronutrients: nitrogen $(\mathrm{N})$, phosphorus $(\mathrm{P})$, potassium $(\mathrm{K})$, calcium $(\mathrm{Ca})$, magnesium $(\mathrm{Mg})$, iron $(\mathrm{Fe})$, manganese $(\mathrm{Mn})$, zinc $(\mathrm{Zn})$, copper $(\mathrm{Cu})$, and boron $(\mathrm{B})$. $\mathrm{N}$ concentration was determined after mineralization with sulphuric acid by "Kjeldahl method" (Bremner, 1965). P, K, Ca, Mg, Fe, Mn, Zn, $\mathrm{Cu}$, and $\mathrm{B}$ concentrations were determined by dry ashing at $400{ }^{\circ} \mathrm{C}$ for $24 \mathrm{~h}$, dissolving the ash in $1: 25 \mathrm{HCl}$, and assaying the solution obtained using an inductively coupled plasma emission spectrophotometer (ICP Iris; Thermo Optek, Milano, Italy) (Karla, 1998).

Chemicals and standards. Pure caffeoylquinic acids and flavonoids to be determined were purchased as certified reference materials from Sigma (St. Louis, MO). Individual stock solutions $\left(500 \mu \mathrm{g} \cdot \mathrm{mL}^{-1}\right)$ were prepared in pure methanol with sonication and then stored at $-30{ }^{\circ} \mathrm{C}$ for up to $5 \mathrm{~d}$. Working standard solutions were prepared daily, in amber glass flasks, by diluting combined aliquots of the stock solutions in the highperformance liquid chromatography (HPLC) mobile phase.

All the solvents and reagents used to prepare standard solutions and to extract polyphenols (methanol, ethyl acetate, formic acid) were analytical-grade reagents, whereas methanol for chromatographic analyses was HPLC-grade; all the solvents were obtained from Merck (Darmstadt, Germany). Formic acid to be used as a mobile phase additive was of liquid chromatography-mass spectroscopygrade from Sigma and water was MilliQ-grade.

Determination of total phenolics. One gram of each dried leaf sample was extracted in $25+25 \mathrm{~mL}$ of an ethanol-water $(70: 30, \mathrm{v} / \mathrm{v})$ mixture to which formic acid was added at a concentration of $10 \mathrm{~mm}$. The extraction was carried out by an Ultra-Turrax homogenizer and solids were removed by centrifugation (503 $\mathrm{g}$ for $5 \mathrm{~min}$ ). The concentration of total phenolic compounds in each extract was then determined by the Folin-Ciocalteu method. Aliquots $(250 \mu \mathrm{L})$ of each artichoke and cardoon extract were mixed with $1 \mathrm{~mL}$ of pure water, $500 \mu \mathrm{L}$ of Folin-Ciocalteu reagent (Sigma), and $1.5 \mathrm{~mL}$ of $1 \mathrm{M}$ sodium carbonate. Absorbance was recorded at $765 \mathrm{~nm}$ after $40 \mathrm{~min}$ at $20{ }^{\circ} \mathrm{C}$ in the dark. A calibration curve was prepared using aliquots of gallic acid ethanolic solutions and the results were expressed as gallic acid equivalents (milligrams gallic acid per gram of dry weight).

Determination of target polyphenols. Both the target caffeoylquinic acids (cynarin, caffeic, chlorogenic, and ferulic acid) and the flavonoids (apigenin, luteolin, silybin, and miricetin) were determined by liquid chromatography followed by tandem mass spectrometry with an electrospray ionization source (LC-ESI/MS/MS). A 1200 series liquid chromatograph system equipped with quaternary pump, electrospray ionization system, and coupled to a G6410A triple quadrupole mass spectrometer detector (all from Agilent Technologies, Santa Clara, CA) was used. The instrument was operating in the negative mode, and each target analyte was quantified by the external standard method.

The plant material $(1 \mathrm{~g})$ was extracted by Ultra-Turrax in $10+5+5 \mathrm{~mL}$ of a methanol + ethyl acetate $(4: 1 \mathrm{v} / \mathrm{v})$ mixture. After centrifugation (503 $\mathrm{g}$ for $8 \mathrm{~min}$ ), the extract was diluted with the mobile phase, filtered through a $0.45-\mu \mathrm{m}$ cellulose membrane, and then analyzed by reversed phase LC-MS/MS using a Kinetex C18 column $(75 \times 2.1 \mathrm{~mm}, 2.6 \mu \mathrm{m})$ from Phenomenex (Torrance, CA). The solvent system used water (Solvent $A$ ) and methanol (Solvent B); formic acid was added to both mobile phases at the concentration of $0.1 \% \mathrm{v} / \mathrm{v}$. Data handling was performed by the MassHunter software under Multiple Reaction Monitoring (MRM) acquisition.

The gradient was designed to decrease Solvent A from $45 \%$ at $0 \mathrm{~min}$ to $40 \%$ at $3 \mathrm{~min}$, held until $4 \mathrm{~min}$, and a post-run time of $2 \mathrm{~min}$ was adopted. The flow was $0.22 \mu \mathrm{L} \cdot \mathrm{min}^{-1}$, the injection volume was $5 \mu \mathrm{L}$, and the drying gas was $\mathrm{N}$ at the temperature of $340{ }^{\circ} \mathrm{C}$ and fluxing at $9 \mathrm{~L} \cdot \mathrm{min}^{-1}$. Capillary voltage was set to $4000 \mathrm{~V}$ and the nebulizer was operating at 20 psi. Dwell time was $70 \mathrm{~ms}$ and resolution was set too wide for both precursor and product ions in each MRM transition.

The instrument was calibrated during each batch of analyses through the injection of standard solutions at four concentrations in triplicate in the range of concentration from 0.2 to $2 \mathrm{mg} \cdot \mathrm{kg}^{-1}$. A calibration curve was built for each analyte and a linear fitting was adopted without forcing to origin; each curve was accepted when the coefficient of determination was greater than 0.99 .

\section{Statistical analysis}

Analysis of variance of the data were calculated using the software package, SPSS 10 for Windows, 2001 (SPSS Inc., Chicago, IL). Orthogonal polynomial contrasts were used to compare nutrient solution concentration effects on selected parameters (Gomez and Gomez, 1983). Regression analyses were conducted to identify relationships between total phenolics expressed as gallic acid equivalents, 
chlorogenic acid, cynarin, luteolin, caffeic acid, and the concentration of the nutrient solution.

\section{Results}

Biomass production. The leaf dry biomass of artichoke and cardoon at 23 and $70 \mathrm{~d}$ after sowing (DAS) and the total leaf biomass were significantly affected by crop and nutrient solution concentration but not by their interaction, whereas the leaf dry biomass at 37,51 , and 91 DAS was only affected by nutrient solution concentration but not by crop and the crop $\times$ nutrient solution concentration interaction (Table 1). Increasing the nutrient solution concentration from 4 to 68 mequiv. $\mathrm{L}^{-1}$ caused a highly statistically significant quadratic trend in total leaf dry biomass with the optimum value recorded at 45.2 mequiv $\cdot \mathrm{L}^{-1}\left(y=-0.0004 x^{2}+0.0362 x+\right.$ 0.4804 where $y=$ leaf dry biomass in $\mathrm{kg} \cdot \mathrm{m}^{-2}$ and $x$ is the nutrient concentration in mequiv. $\left.\mathrm{L}^{-1} ; R^{2}=0.96\right)$. Moreover, irrespective of the nutrient solution concentration, the leaf dry biomass at 23 and 70 DAS and the total biomass were significantly higher by $11.1 \%, 17.6 \%$, and $5.6 \%$, respectively, in cardoon in comparison with those recorded in globe artichoke (Table 1).

The leaf number of artichoke and cardoon had a similar trend to the leaf dry biomass with a significantly higher values recorded in cardoon than in artichoke cultivars (Table 2). When averaged over nutrient solution concentration, the number of leaves per plant at 23,37 , and 91 DAS and the total number of leaves were significantly higher by $7.6 \%$, $14.2 \%, 23.1 \%$, and $10.2 \%$, respectively, in cardoon than with artichoke (Table 2). Finally, increasing the nutrient solution concentration from 4 to 68 mequiv. $\mathrm{L}^{-1}$ caused a highly statistically significant quadratic trend in total number of leaves per plant with the highest values recorded at 53.9 mequiv. $\mathrm{L}^{-1}$ $\left(y=-0.0017 x^{2}+0.1832 x+9.8831\right.$ where $y=$ leaf number in $\mathrm{n}$. plant ${ }^{-1}$ and $x$ is the nutrient concentration in mequiv. $\mathrm{L}^{-1} ; R^{2}=0.96$ ) (Table 2).

Mineral composition. The macro- and microelements concentrations in cardoon and artichoke leaf tissue as a function of crop and nutrient solution concentration are displayed in Tables 3 and 4 . The concentration of $\mathrm{N}, \mathrm{K}, \mathrm{Ca}$, and $\mathrm{Mg}$ in leaf tissue was significantly affected by nutrient solution concentration but not by crop and the crop $\times$ nutrient solution concentration interaction (Table 3). Moreover, no significant difference among treatments was observed for $\mathrm{P}$ concentration (average $9.55 \mathrm{~g} \cdot \mathrm{kg}^{-1}$ dry weight). The concentration of $\mathrm{N}$ and $\mathrm{Ca}$ increased quadratically and linearly, whereas the concentration of $\mathrm{K}$ and $\mathrm{Mg}$ increased only linearly in response to an increase in nutrient solution concentration (Table 3 ).

The effect of nutrient solution concentration on tissue micronutrient concentrations ( $\mathrm{Fe}, \mathrm{Mn}, \mathrm{Cu}$, and $\mathrm{B}$ ) was highly significant (Table 4). The tissue concentrations of Fe, $\mathrm{Cu}$, and $\mathrm{B}$ declined linearly and those of $\mathrm{Mn}$ decreased linearly and quadratically as the

Table 1. Mean effects of crop and nutrient solution concentration on leaf dry biomass.

\begin{tabular}{|c|c|c|c|c|c|c|}
\hline \multirow[b]{2}{*}{ Treatment } & \multicolumn{6}{|c|}{ Leaf dry biomass $\left(\mathrm{kg} \cdot \mathrm{m}^{-2}\right)$} \\
\hline & $23 \mathrm{DAS}^{\mathrm{z}}$ & 37 DAS & 51 DAS & 70 DAS & 91 DAS & Total \\
\hline \multicolumn{7}{|l|}{ Crop } \\
\hline Artichoke & 0.18 & 0.32 & 0.17 & 0.17 & 0.23 & 1.07 \\
\hline Cardoon & 0.20 & 0.31 & 0.19 & 0.20 & 0.24 & 1.13 \\
\hline \multicolumn{7}{|c|}{ Solution concentration (mequiv. $\mathrm{L}^{-1}$ ) } \\
\hline 4 & 0.12 & 0.18 & 0.07 & 0.13 & 0.10 & 0.60 \\
\hline 20 & 0.16 & 0.30 & 0.20 & 0.20 & 0.25 & 1.12 \\
\hline 36 & 0.21 & 0.36 & 0.19 & 0.20 & 0.25 & 1.21 \\
\hline 52 & 0.26 & 0.38 & 0.23 & 0.20 & 0.31 & 1.39 \\
\hline 68 & 0.20 & 0.34 & 0.22 & 0.18 & 0.24 & 1.19 \\
\hline \multicolumn{7}{|l|}{ Significance } \\
\hline Crop (C) & * & NS & NS & $*$ & NS & $*$ \\
\hline Solution concentration (S) & *** & $* * *$ & $* * *$ & $* * *$ & $* * *$ & $* * *$ \\
\hline Linear & * & * & * & NS & * & * \\
\hline Quadratic & $* * *$ & $* * *$ & $* * *$ & $* * *$ & $* * *$ & $* * *$ \\
\hline $\mathrm{C} \times \mathrm{S}$ & NS & NS & NS & NS & NS & NS \\
\hline
\end{tabular}

${ }^{\mathrm{x}} \mathrm{DAS}=$ days after sowing.

Ns, * ***Nonsignificant or significant at $P<0.05$, and 0.001 , respectively.

Table 2. Mean effects of crop and nutrient solution concentration on leaf number.

\begin{tabular}{|c|c|c|c|c|c|c|}
\hline \multirow[b]{2}{*}{ Treatment } & \multicolumn{6}{|c|}{ Leaf number (n./plant) } \\
\hline & $23 \mathrm{DAS}^{\mathrm{z}}$ & 37 DAS & $51 \mathrm{DAS}$ & 70 DAS & 91 DAS & Total \\
\hline \multicolumn{7}{|l|}{$\overline{\text { Crop }}$} \\
\hline Artichoke & 3.9 & 2.1 & 1.6 & 2.5 & 2.6 & 12.7 \\
\hline Cardoon & 4.2 & 2.4 & 1.7 & 2.6 & 3.2 & 14.0 \\
\hline \multicolumn{7}{|c|}{ Solution concentration (mequiv. $\mathrm{L}^{-1}$ ) } \\
\hline 4 & 3.8 & 1.8 & 1.1 & 2.2 & 1.5 & 10.6 \\
\hline 20 & 3.9 & 2.3 & 1.7 & 2.6 & 2.6 & 13.0 \\
\hline 36 & 4.0 & 2.3 & 1.7 & 2.8 & 3.0 & 13.8 \\
\hline 52 & 4.4 & 2.5 & 1.7 & 2.7 & 3.9 & 15.3 \\
\hline 68 & 3.9 & 2.4 & 2.1 & 2.5 & 3.4 & 14.3 \\
\hline \multicolumn{7}{|l|}{ Significance } \\
\hline Crop (C) & * & ** & NS & NS & $* * *$ & $* * *$ \\
\hline Solution concentration (S) & * & $* *$ & $* * *$ & $*$ & $* * *$ & $* * *$ \\
\hline Linear & NS & $*$ & $* * *$ & NS & $* *$ & $* *$ \\
\hline Quadratic & $*$ & $* *$ & $*$ & $* *$ & $* * *$ & $* * *$ \\
\hline $\mathrm{C} \times \mathrm{S}$ & NS & NS & NS & NS & NS & NS \\
\hline
\end{tabular}

${ }^{\mathrm{z}} \mathrm{DAS}=$ days after sowing.

Ns, *,**,**Nonsignificant or significant at $P<0.05,0.01$, and 0.001 , respectively.

Table 3. Mean effects of crop and nutrient solution concentration on macronutrient composition of leaves.

\begin{tabular}{|c|c|c|c|c|c|}
\hline \multirow[b]{2}{*}{ Treatment } & \multicolumn{5}{|c|}{ Macronutrients (g. $\mathrm{kg}^{-1}$ dry wt) } \\
\hline & $\mathrm{N}$ & $\mathrm{P}$ & $\mathrm{K}$ & $\mathrm{Ca}$ & $\mathrm{Mg}$ \\
\hline \multicolumn{6}{|l|}{$\overline{\text { Crop }}$} \\
\hline Artichoke & 45.0 & 9.6 & 26.9 & 11.4 & 3.0 \\
\hline Cardoon & 45.9 & 9.5 & 25.9 & 11.1 & 2.8 \\
\hline \multicolumn{6}{|c|}{ Solution concentration (mequiv $\cdot \mathrm{L}^{-1}$ ) } \\
\hline 4 & 31.2 & 8.4 & 22.5 & 8.9 & 2.6 \\
\hline 20 & 46.4 & 9.8 & 25.4 & 12.2 & 2.6 \\
\hline 36 & 48.2 & 9.9 & 28.1 & 11.9 & 2.8 \\
\hline 52 & 48.9 & 10.0 & 27.5 & 11.5 & 3.1 \\
\hline 68 & 49.9 & 9.7 & 28.7 & 11.7 & 3.2 \\
\hline \multicolumn{6}{|l|}{ Significance } \\
\hline Crop (C) & NS & NS & NS & NS & NS \\
\hline Solution concentration (S) & $* * *$ & NS & $* * *$ & $* *$ & * \\
\hline Linear & $* * *$ & NS & $* * *$ & $*$ & $*$ \\
\hline Quadratic & $* *$ & NS & NS & ** & NS \\
\hline $\mathrm{C} \times \mathrm{S}$ & NS & NS & NS & NS & NS \\
\hline
\end{tabular}

$\mathrm{N}=$ nitrogen; $\mathrm{P}=$ phosphorus; $\mathrm{K}=$ potassium; $\mathrm{Ca}=$ calcium; $\mathrm{Mg}=$ magnesium.

Ns, ${ }^{*}, * *, * * *$ Nonsignificant or significant at $P<0.05,0.01$, and 0.001 , respectively.

external nutrient concentration increased. Finally, irrespective of nutrient solution, the concentrations of $\mathrm{Fe}, \mathrm{Mn}$, and $\mathrm{Zn}$ were significantly higher by $10.2 \%, 19.4 \%$, and $18.2 \%$, respectively, in cardoon leaf tissue in comparison with artichoke, whereas an opposite trend was observed for B (Table 4).

Total and target polyphenols in leaves. Although chromatographic resolution was limited, the analysis of target polyphenols was robust thanks to the highly specific and sensitive detection by tandem mass spectrometry. Indeed, the specificity arising from MRM in tandem MS acquisition provided selective analyses for each target compound. The linear dynamic range was also adequate, being the coefficient of determination higher than 0.99 in all cases over a 0.2 to $2 \mathrm{mg} \cdot \mathrm{L}^{-1}$ interval. 
Precision, expressed as repeatability, was below $6.2 \%(n=5)$ and extraction efficiency was higher than $93 \%$.

The total polyphenols were highly $(P<$ $0.001)$ influenced by nutrient solution concentration, crop, and their interaction (data not shown). The relationship resulting from regression analysis of the total polyphenols expressed as gallic acid equivalents over nutrient solution concentration was best described by a power function (Fig. 1). The gallic acid concentration in both cardoon and artichoke decreased with increasing the nutrient solution concentration from 4 to 68 mequiv. $\mathrm{L}^{-1}$. Moreover, when averaged over nutrient solution concentration, the highest values of gallic acid were recorded in cardoon than in artichoke (average 13.3 vs. $\left.9.9 \mathrm{~g} \cdot \mathrm{kg}^{-1}\right)$.

Concerning the quantitative and qualitative profiles of the individual polyphenols (flavones and caffeoylquinic acids), significant differences among crops, nutrient solution concentration, and the crop $\times$ nutrient solution concentration interaction were found (Fig. 2). Among the caffeoylquinic acid derivatives, the chlorogenic acid was the predominant compound followed by cynarin, and finally caffeic acid, whereas the ferulic

Table 4. Mean effects of crop and nutrient solution concentration on micronutrient composition of leaves.

\begin{tabular}{llllll}
\hline \multirow{2}{*}{ Treatment } & \multicolumn{5}{c}{ Micronutrients $\left(\mathrm{mg} \cdot \mathrm{kg}^{-1} \mathrm{DW}\right)$} \\
\cline { 2 - 6 } Crop & $\mathrm{Fe}$ & $\mathrm{Mn}$ & $\mathrm{Zn}$ & $\mathrm{Cu}$ & $\mathrm{B}$ \\
$\quad$ Artichoke & & & & & \\
$\quad$ Cardoon & 26.4 & 40.7 & 17.5 & 2.4 & 20.0 \\
$\quad$ Solution concentration (mequiv. $\left.\mathrm{L}^{-1}\right)$ & 29.1 & 48.6 & 20.7 & 2.4 & 17.1 \\
$\quad 4$ & & & & & \\
20 & 30.4 & 53.7 & 17.3 & 2.8 & 23.1 \\
36 & 28.7 & 46.4 & 19.1 & 2.5 & 20.8 \\
52 & 27.3 & 41.5 & 20.3 & 2.5 & 16.9 \\
$\quad 68$ & 26.3 & 40.5 & 20.6 & 2.1 & 16.4 \\
Significance & 26.1 & 41.1 & 18.2 & 2.0 & 15.6 \\
Crop (C) & & & & & \\
Solution concentration (S) & $* * *$ & $* * *$ & $* *$ & NS & $* *$ \\
$\quad$ Linear & $* *$ & $* * *$ & NS & $* *$ & $* * *$ \\
$\quad$ Quadratic & $* *$ & $* * *$ & NS & $* * *$ & $* * *$ \\
C $\times$ S & NS & $*$ & NS & NS & NS \\
DW & NS & NS & NS & NS & NS \\
\hline
\end{tabular}

$\mathrm{DW}=$ dry weight; $\mathrm{Fe}=$ iron; $\mathrm{Mn}=$ manganese; $\mathrm{Zn}=$ zinc; $\mathrm{Cu}=$ copper; $\mathrm{B}=$ boron.

$\mathrm{NS}, *, * *, * * *$ Nonsignificant or significant at $P<0.05,0.01$, and 0.001 , respectively.

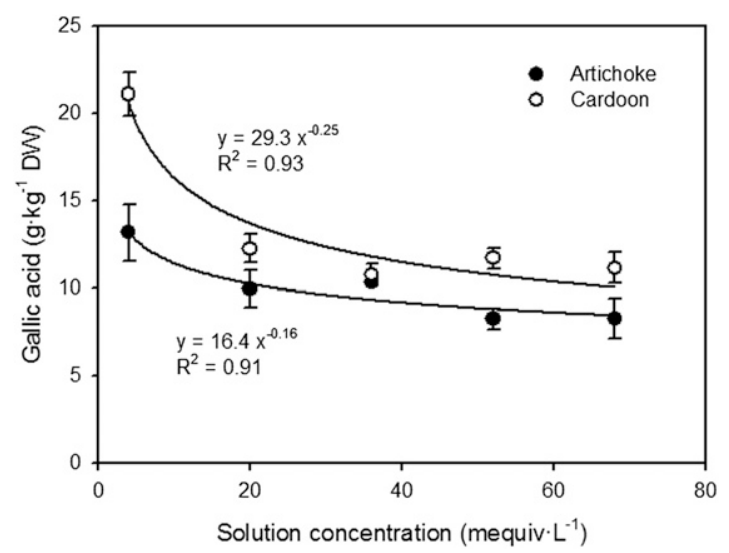

Fig. 1. Relationship between total polyphenols expressed as gallic acid equivalents and nutrient solution concentration in leaves of artichoke and cultivated cardoon. Vertical bars indicate $\pm \mathrm{SE}$ of means, their absence indicates the size was less than the symbol. high or low concentrations of nutrient solutions (Savvas and Adamidis, 1999). In the current experiment, dry shoot biomass and leaf number of artichoke and cardoon were significantly reduced especially at low (4 and 20 mequiv $\left.\cdot \mathrm{L}^{-1}\right)$ and high $\left(68\right.$ mequiv $\left.\cdot \mathrm{L}^{-1}\right)$ fertilizer concentrations, probably as a result of nutrient deficiencies and osmotic stress, respectively. The reduction of crop growth resulting from osmotic effect has been reported previously for many vegetable crops (Colla et al., 2006a, 2006b, 2008, 2010, 2012; Rouphael et al., 2006, 2012). The main effects of high or low nutrient solution concentration were the reduction of growth rate as a result of smaller leaves, shorter stature, and fewer leaves. These results are consistent with the findings of Fallovo et al. (2009a) who reported that the marketable fresh yield, dry shoot biomass, and leaf area index of leafy lettuce were reduced at low (4 and 20 mequiv $\cdot \mathrm{L}^{-1}$ ) and high (68 mequiv. $\left.\mathrm{L}^{-1}\right)$ solution concentrations. Moreover, the results of the present study suggest that artichoke and cardoon gave maximum biomass production and leaf number at 45 and 54 mequiv $\cdot \mathrm{L}^{-1}$, respectively.

In our experiment, marked differences emerged in the plant growth parameters (leaf dry biomass and number) of the tested crops (Tables 1 and 2). The cardoon showed higher biomass and leaf number (average $1.13 \mathrm{~kg} \cdot \mathrm{m}^{-2}$ and $14.0 \mathrm{n} . /$ plant, respectively) than those observed in artichoke (average $1.07 \mathrm{~kg} \cdot \mathrm{m}^{-2}$ and $12.7 \mathrm{n}$./plant, respectively). The marked differences found between cardoon and artichoke crops suggest the possibility of exploiting this kind of variability in breeding programs with the aim of selecting phytochemical crops with higher biomass production.

The effect of crop on macro- and micronutrient concentration in leaves was less pronounced than the effect caused by the nutrient solution concentration (Tables 3 and 4). Among the macroelements studied, $\mathrm{N}$ was the mineral with a higher concentration with a mean concentration of $45.4 \mathrm{~g} \cdot \mathrm{kg}^{-1}$ dry weight followed by $\mathrm{K}$ with a mean concentration of $26.4 \mathrm{~g} \cdot \mathrm{kg}^{-1}$ dry weight (Table 3 ). Among, the microminerals studied here, Mn was the most abundant element with a mean concentration of $44.6 \mathrm{mg} \cdot \mathrm{kg}^{-1}$ dry weight compared with other microelements $(27.7,19.1,2.4$, and $18.5 \mathrm{mg} \cdot \mathrm{kg}^{-1}$ dry weight for $\mathrm{Fe}, \mathrm{Zn}, \mathrm{Cu}$, and $B$, respectively) (Table 4).

Compared with the mineral composition of other vegetables reported in the literature, the leaf of artichoke and cardoon represents a good source of $\mathrm{K}$ and especially $\mathrm{Fe}$ and $\mathrm{Zn}$, two of the most important essential microelements in human nutrition. Their deficiency leads to several disorders such as growth retardation, weakened immunological defense, and anemia (Olivares et al., 1999).

Pharmaceutical properties of artichoke leaves are linked to their special chemical composition, which includes high levels of polyphenolic compounds and inulin. C. cardunculus is well known to contain a high concentration of bioactive compounds 


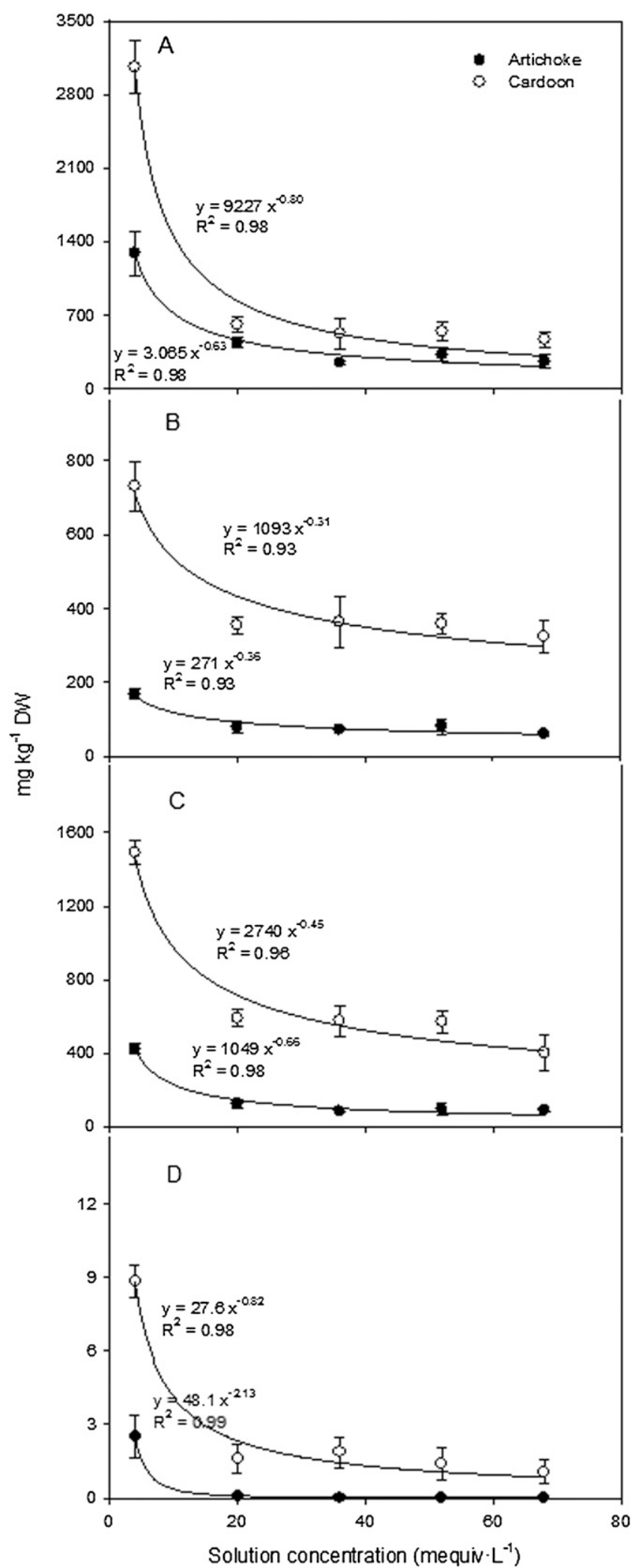

Fig. 2. Relationships between chlorogenic acid (A), cynarin (B), luteolin (C), caffeic acid (C) and nutrient solution concentration in leaves of artichoke and cardoon. Vertical bars indicate $\pm \mathrm{SE}$ of means, their absence indicates the size was less than the symbol.

such as flavonoids and phenolic acids (including caffeoylquinic acids). These are widely studied as a result of their multiple biological activities (Holst and Williamson, 2008). In the genus Cynara, mono- and dicaffeoylquinic acids and luteolin and apigenin derivatives have been documented as the major compounds (Schütz et al., 2004). Among the caffeoylquinic acid derivatives, the chlorogenic acid was the predominant compound in artichoke and cardoon leaf tissue with a mean concentration of $778 \mathrm{mg} \cdot \mathrm{kg}^{-1}$ dry weight followed by cynarin (average $259 \mathrm{mg} \cdot \mathrm{kg}^{-1}$ dry weight), and finally by caffeic acid (average $1.7 \mathrm{mg} \cdot \mathrm{kg}^{-1}$ dry weight). In contrast, lowest quantities were observed for flavonoid in particular luteolin (average $44.5 \mathrm{mg} \cdot \mathrm{kg}^{-1}$ dry weight).

It is known that the concentration of flavonoids and phenolic acids varies as a function of many factors such as environment, cultural practices, biotic and abiotic stresses, and genotype (Pandino et al., 2010). In general, increased nutrient solution concentration reduces the yield of vegetable crops but may improve their nutritional quality, as observed in plants grown in both soil and soilless culture (Francois and Maas, 1994; Rouphael et al., 2006, 2010). In this study, increasing nutrient solution concentration from 4 to 68 mequiv. $\mathrm{L}^{-1}$ decreased the quality aspects of leaves by decreasing the total polyphenols, chlorogenic acid, cynarin, caffeic acid, and luteolin concentration, especially when the nutrient solution concentration increased from 4 to 20 mequiv. $\mathrm{L}^{-1}$ (Figs. 1 and 2). The reduction in phenolic acids and flavonoids in leaves of artichoke and cardoon with the increase of nutrient concentration suggests that the secondary metabolism of plant was promoted by low nutrient availability as observed by Kraus et al. (2004).

The concentration of polyphenols in artichoke and cardoon leaves appears strongly influenced by genetic factors as previously demonstrated in other crops including blackberry (Connor et al., 2005), potato (Reddivari et al., 2007), garlic (Beato et al., 2011), faba bean (Chaieb et al., 2011), and tomato (Vallerdú-Queralt et al., 2011). In the current study, the highest amount of chlorogenic acid was found in cardoon 'Bianco Avorio' compared with the artichoke cv. Romolo (Fig. 2). This result is very important because in vivo rat studies have demonstrated the antioxidant and anticarcinogenic properties of chlorogenic acid (Gonthier et al., 2003). The chlorogenic acid is usually poorly absorbed in the small intestine but capable of providing higher yields of microbial metabolites, active compounds responsible for the biological properties attributed to dietary polyphenols (Gonthier et al., 2003). The high level of chlorogenic acid found in cardoon cultivar Bianco Avorio could be explained by its central role as a substrate for many biochemical reactions producing several phenolic acids (Wittemer et al., 2005), which are highly represented in artichoke. Similar to chlorogenic acid, the highest concentration of cynarin, a polyphenolic compound typical of $C$. cardunculus and important for its choleretic activity (Gebhardt, 1997; Gebhardt and Beck, 1996), was also observed in cardoon (Fig. 2). Finally, the highest concentration of flavonoid luteolin was also observed in cardoon.

\section{Conclusions}

Increasing fertilizer concentrations linearly or quadratically increased plant growth 
(leaf dry biomass and number) but negatively affected the leaf quality in both artichoke and cardoon by decreasing total polyphenols, chlorogenic acid, caffeic acid, cynarin, and luteolin concentration. The caffeoylquinic acids and luteolin concentrations were higher in cardoon leaf tissue than in that of artichoke, suggesting the potential use of cardoon as valuable sources of phenolic acids and flavonoids.

\section{Literature Cited}

Beato, V.M., F. Orgaz, F. Mansilla, and A. Montaño. 2011. Changes in phenolics compounds in garlic (Allium sativum L.) owing to the cultivar and location of growth. Plant Foods Hum. Nutr. doi: 10.1007/s11130-011-0236-2.

Bremner, J.M. 1965. Total nitrogen, p. 1149-1178. In: Black, C.A., D.D. Evans, I.L. White, L.E. Ensminger, and F.E. Clark (eds.). Methods of soil analysis. Agron. Mono. 9, Part 2.

Brown, J.E. and C.A. Rice-Evans. 1998. Luteolinrich artichoke extract protects low density lipoprotein from oxidation in vitro. Free Radic. Res. 29:247-255.

Bruneton, J. 1995. Pharmacognosy phytochemistry medicinal plants. Lavoisier Publishing, Secaucus, NY. p. 218-219.

Chaieb, N., J.L. González, M. López-Mesas, M. Bouslama, and M. Valiente. 2011. Polyphenols content and antioxidant capacity of thirteen faba bean (Vicia faba L.) genotypes cultivated in Tunisia. Food Res. Intl. 44:970 977.

Colla, G., Y. Rouphael, M. Cardarelli, D. Massa, A. Salerno, and E. Rea. 2006a. Yield, fruit quality and mineral composition of grafted melon plants grown under saline conditions. J. Hort. Sci. Biotechnol. 81:146-152.

Colla, G., Y. Rouphael, M. Cardarelli, and E. Rea. 2006b. Effect of salinity on yield, fruit quality, leaf gas exchange, and mineral composition of grafted watermelon plants. HortScience 41: 622-627.

Colla, G., Y. Rouphael, M. Cardarelli, M. Tullio, C.M. Rivera, and E. Rea. 2008. Alleviation of salt stress by arbuscular mycorrhizal in zucchini plants grown at low and high phosphorus concentration. Biol. Fertil. Soils 44:501-509.

Colla, G., Y. Rouphael, C. Leonardi, and Z. Bie. 2010. Role of grafting in vegetable crops grown under saline conditions. Sci. Hort. 127:147155.

Colla, G., Y. Rouphael, E. Rea, and M. Cardarelli. 2012. Grafting cucumber plants enhance tolerance to sodium chloride and sulphate salinization. Sci. Hort. 135:177-185.

Connor, A.M., C.E. Finn, T.K. McGhie, and P.A. Alspach. 2005. Genetic and environmental variation in anthocyanins and their relationship to antioxidant activity in blackberry and hybrid berry cultivars. J. Amer. Soc. Hort. Sci. 130: 680-687.

Dranik, L.I., L.G. Dolganenko, J. Slapke, and N. Thoma. 1996. Chemical composition and medical usage of Cynara scolymus L. Rastit. Resur. 32:98-104.

Fallovo, C., Y. Rouphael, E. Rea, A. Battistelli, and G. Colla. 2009a. Nutrient solution concentration and growing season affect yield and quality of Lactuca sativa L. var. acephala in floating raft culture. J. Sci. Food Agr. 89:16821689.

Fallovo, C., Y. Rouphael, M. Cardarelli, E. Rea, A. Battistelli, and G. Colla. 2009b. Yield and quality of leafy lettuce in response to nutrient solution composition and growing season. J. Agr. Food Environ. 7:456-462.

FAO Statistical Database. 2011. <http://www.faostat. org/>.

Francois, L.E. and E.V. Maas. 1994. Crop response and management of salt-affected soils, p. 449343. In: Pessarakli, M. (ed.). Handbook of plant and crop stress. Marcel Dekker, New York, NY.

Fratianni, F., M. Tucci, M. De Palma, R. Pepe, and F. Nazzaro. 2007. Polyphenolic composition in different parts of some cultivars of globe artichoke [Cynara cardunculus L. var. scolymus (L.) Fiori]. Food Chem. 104:1282-1286.

Gebhardt, R. 1997. Antioxidative and protective properties of extracts from leaves of the artichoke (Cynara scolymus L.) against hydroperoxide-induced oxidative stress in cultured rat hepatocytes. Toxicol. Appl. Pharmacol. 144:279-286.

Gebhardt, R. and H. Beck. 1996. Differential effects of garlic-derived organosulfides on cholesterol biosynthesis in primary rat hepatocyte cultures. Lipids 1:1269-1276.

Gomez, K.A. and A.A. Gomez. 1983. Comparison between treatments means, p. 187-240. In: Gomez, K.A. and A.A. Gomez (eds.). Statistical procedures for agricultural research. 2nd Ed. John Wiley \& Sons, New York, NY.

Gonthier, M.P., M.A. Verny, C. Besson, C. Remesy, and A. Scalbert. 2003. Chlorogenic acid bioavailability largely depends on its metabolism by the gut microflora in rats. J. Nutr. 133:18531859.

Holst, B. and G. Williamson. 2008. Nutrients and phytochemicals: From bioavailability to bioefficacy beyond antioxidants. Curr. Opin. Biotechnol. 19:73-82.

James, E.C. and M.W. van Iersel. 2001. Fertilizer concentration affects growth and flowering of subirrigated petunias and begonias. HortScience 36:40-44.

Kader, A.A. 2008. Flavor quality of fruits and vegetables. J. Sci. Food Agr. 88:1863-1868.

Karla, Y.P. 1998. Handbook of reference methods for plant analysis. CRC Press Inc., Boca Raton, FL. p. 165-170.

Kraft, K. 1997. Artichoke leaf extracts. Recent findings reflecting effects on lipids metabolism, liver and gastrointestinal tracts. Phytomedicine 4:369-378.

Kraus, T.E.C., R.J. Zasoski, and R.A. Dahlgren. 2004. Fertility and $\mathrm{pH}$ effects on polyphenol and condensed tannin concentrations in foliage and roots. Plant Soil 262:95-109.

Lombardo, S., G. Pandino, G. Mauromicale, M. Knödler, R. Carle, and A. Schieber. 2010. Influence of genotype, harvest time and plant part on polyphenolic composition of globe artichoke [Cynara cardunculus L. var. scolymus (L.) Fiori]. Food Chem. 119:1175-1181.

Mak, A.T.Y. and D.M. Yeh. 2001. Nitrogen nutrition of Spathiphyllum 'Sensation' grown in sphagnum peat- and coir-based media with two irrigation methods. HortScience 36:645649.

Martino, V., N. Caffini, J.D. Phillipson, A. Lappa, A. Tchernitchin, G. Ferraro, S. Debenedelti, H. Schilcher, and C. Acevedo. 1999. Identification and characterization of antimicrobial components in leaf extracts of globe artichoke (Cynara scolymus L.). Acta Hort. 501:111-114.

Olivares, M., T. Walter, E. Hertrampf, and F. Pizarro. 1999. Anaemia and iron deficiency disease in children. BMJ 55:534-543.

Pandino, G., F.L. Courts, S. Lombardo, G. Mauromicale, and G. Williamson. 2010. Caffeoylquinic acids and flavonoid in the immature inflorescence of globe artichoke, wild cardoon, and cultivated cardoon. J. Agr. Food Chem. 58:1026-1031.

Perez-Garcia, F., T. Adzet, and S. Canigueral. 2000. Activity of artichoke leaf extract on reactive oxygen species in human leukocytes. Free Radic. Res. 3:661-665.

Reddivari, L., A.L. Hale, and C. Miller. 2007. Genotype, location, and year influence antioxidant activity, carotenoid content, phenolic content, and composition in specialty potatoes. J. Agr. Food Chem. 55:8073-8079.

Resh, H.M. 1997. Hydroponic food production. Woodbridge Press, Santa Barbara, CA.

Rottenberg, A. and D. Zohary. 1996. The wild relatives and the wild ancestry of the cultivated artichoke. Genet. Resources Crop Evol. 43:5358.

Rouphael, Y., M. Cardarelli, E. Rea, A. Battistelli, and G. Colla. 2006. Comparison of the subirrigation and drip-irrigation system for greenhouse zucchini squash production using saline and non-saline nutrient solutions. Agr. Water Mgt. 82:99-117.

Rouphael, Y., M. Cardarelli, E. Rea, and G. Colla. 2008. The influence of irrigation system and nutrient solution concentration on potted geranium production under various conditions of radiation and temperature. Sci. Hort. 118:328-337.

Rouphael, Y., M. Cardarelli, E. Rea, and G. Colla. 2012. Improving melon and cucumber photosynthetic activity, mineral composition, and growth performance under salinity stress by grafting onto Cucurbita hybrid rootstocks. Photosynthetica 50:180-188.

Rouphael, Y. and G. Colla. 2009. The influence of drip-irrigation or subirrigation on zucchini squash grown in closed-loop substrate culture with high and low nutrient solution concentrations. HortScience 44:306-311.

Rouphael, Y., D. Schwarz, A. Krumbein, and G. Colla. 2010. Impact of grafting on product quality of fruit vegetables. Sci. Hort. 7:172179.

Savvas, D. and K. Adamidis. 1999. Automated management of nutrient solutions based on target electrical conductivity, $\mathrm{pH}$, and nutrient concentration ratios. J. Plant Nutr. 22:1415-1432.

Schütz, K., D. Kammerer, R. Carle, and A. Schieber. 2004. Identification and quantification of caffeoylquinic acids and flavonoids from artichoke (Cynara scolymus L.) heads, juice, and pomace by HPLC-DAD-ESI/MSn. J. Agr. Food Chem. 52:4090-4096.

Vallerdú-Queralt, A., A. Medina-Remón, M. Martínez-Huélamo, O. Jáuregui, C. AndresLacueva, and R.M. Lamuela-Raventos. 2011. Phenolic profile and hydrophilic antioxidant capacity as chemotaxonomic markers of tomato varieties. J. Agr. Food Chem. 59:39944001.

Van Iersel, M.W. 1999. Fertilizer concentration affects growth and nutrient composition of subirrigated pansies. HortScience 34:660-663.

Wagenbreth, D. 1996. Evaluation of artichoke cultivars for growing and pharmaceutical use. Beitr. Zuchtungsforsch. 2:400-403.

Wang, M., J.E. Simon, I.F. Aviles, K. He, Q. Zheng, and Y. Tadmor. 2003. Analysis of antioxidative phenolic compounds in artichoke (Cynara scolymus L.). J. Agr. Food Chem. 51:601-608.

Wittemer, S.M., M. Ploch, T. Windeck, S.C. Muller, B. Drewelow, and H. Derendorf. 2005. Bioavailability and pharmacokinetics of caffeoylquinic acids and flavonoids after oral administration of artichoke leaf extracts in humans. Phytomedicine 12:28-38. 